\title{
Medication-Induced Esophagitis
}

\author{
Farooq P. Agha ${ }^{1}$, Joanne A.P. Wilson ${ }^{2}$, and Timothy T. Nostrand ${ }^{2}$ \\ Departments of ${ }^{1}$ Radiology and ${ }^{2}$ Internal Medicine (Gastroenterology Section), University of Michigan Hospitals, \\ Ann Arbor, Michigan, USA
}

\begin{abstract}
Clinical, radiographic, and endoscopic features of medication-induced esophagitis (MIE) in 4 patients are described. When the clinical history and symptoms raise a high index of suspicion for MIE, a double-contrast esophagram or endoscopic examination should be performed. The proximal esophagus, particularly the aortic segment, and occasionally the distal esophagus are the sites most commonly affected by MIE. Superficial mucosal erosions, shallow ulcers, and subtle mucosal alterations can be demonstrated by double-contrast esophagrams if careful attention is paid during performance and interpretation of these studies in an appropriate clinical setting.
\end{abstract}

Key words: Esophagus, ulceration - Esophagitis, medication-induced.

Esophageal ulceration caused by oral medication has been reported with increasing frequency during the last decade [1-30]. It may be more common under certain special circumstances. The diagnosis of medication-induced esophagitis (MIE) is usually not made initially unless there is clinical awareness and a high index of suspicion for this entity. The most common site of esophageal involvement is the aortic segment of the esophagus and occasionally the distal esophagus. The spectrum of changes found at endoscopy ranges from mucosal edema, erythema, superficial erosions, and small shallow ulcers, to large or deeper ulcers and strictures. Recently, due to increasing awareness of this entity and routine use of double-contrast radiography at our institution we have diagnosed MIE in 4 patients. We report these cases and review the literature.

Address reprint requests to: Farooq P. Agha, M.D., Box 13, Department of Radiology, University Hospital, 1405 East Ann Street, Ann Arbor, MI 48109, USA

\section{Materials and Methods}

During the last year we have examined 3 patients with suspected MIE using double-contrast esophagography and 1 patient with conventional single-contrast esophagram. The double-contrast technique consisted of examination of the patient in the upright position after ingestion of effervescent granules with $10 \mathrm{ml}$ of water, and $113 \mathrm{~g}$ high-density barium in rapid successive swallows. Serial spot films in the left or right posterior oblique positions were obtained. All patients underwent endoscopic confirmation of esophageal ulcerations or erosions. Complete symptomatic improvement occurred within 3-5 days following withdrawal of the offending medication. Follow-up barium swallows or endoscopy showed resolution of esophageal erosions and ulcerations.

\section{Case Reports}

\section{Case 1}

A 48-year-old white woman who had been in excellent health presented with severe odynophagia of 1 week's duration. The pain had been continuous and exacerbated when she swallowed liquids and solids. The pain was referred to an area just below the sternal notch. She had no nausea, emesis, pyrosis, melena, or hematochezia.

Her past history was significant for tuberculosis treated with chemotherapy and with normal findings on a chest radiograph after therapy. Her only medication was tetracycline $(250 \mathrm{mg})$ taken twice daily for a dermatologic disorder. On questioning, the patient did admit to ingestion of the tetracycline tablets without water at bed time. She began taking this medication at approximately the time of onset of symptoms.

The physical examination was normal with the exception of acne rosacea of the face. Results of routine laboratory studies were normal. A barium swallow using double-contrast technique revealed some hold-up of the barium in the aorticopulmonary segment of the esophagus. The patient was asked to point to the area of pain during barium swallow; the area corresponded to the aortic segment of the esophagus. There were several linear erosions and superficial ulcerations in this area of the esophagus which were not initially appreciated despite exact localization by the patient (Fig. 1A, B). Upper endoscopy performed 1 day later showed discrete small $(2-5 \mathrm{~mm})$ ulcers and erosions circumferentially distributed at approximately $25 \mathrm{~cm}$ from the incisors (Fig. 1C). No stricture or other abnormalities were noted in the esophagus, stomach, or duodenum. 

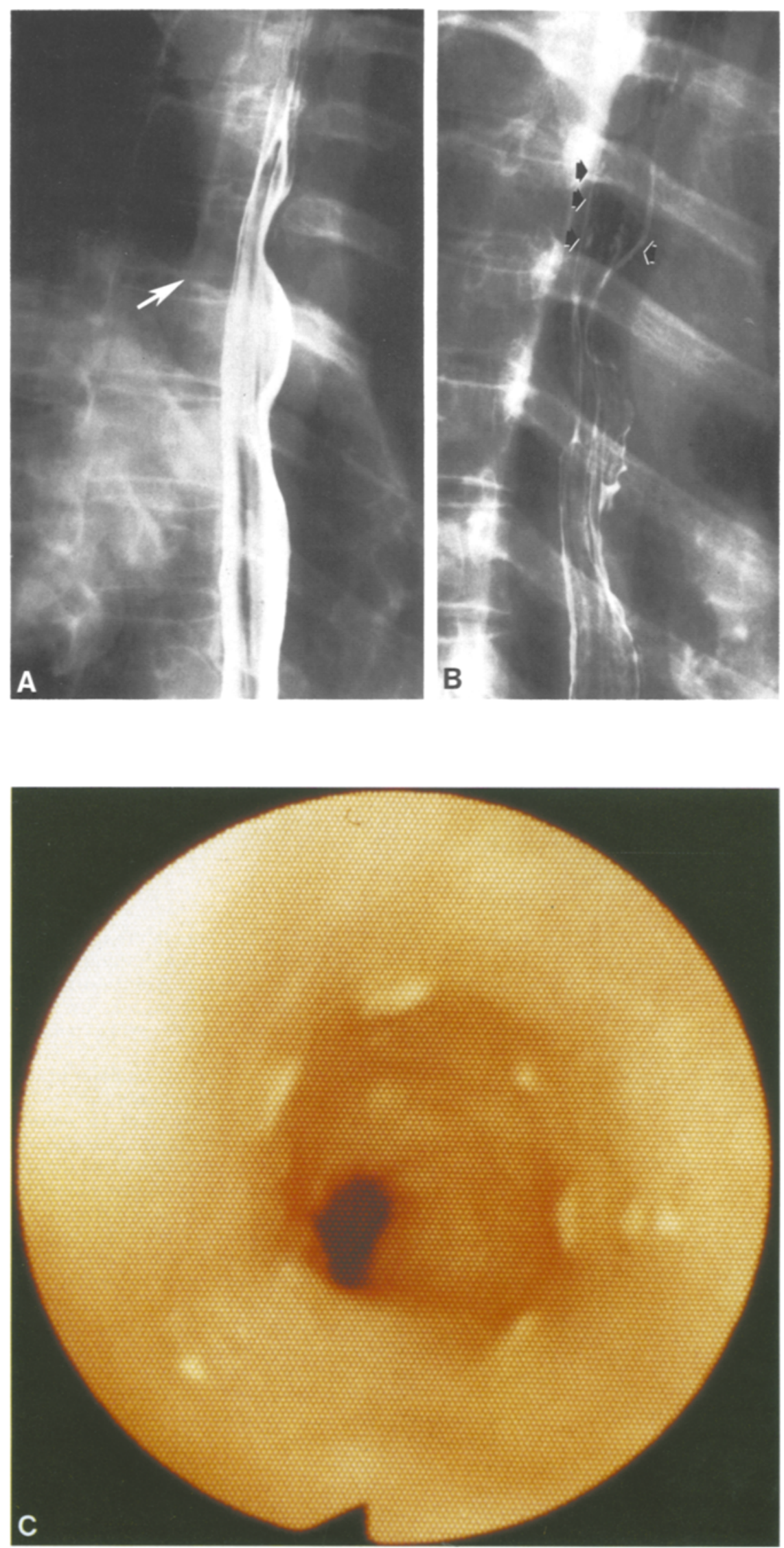

Fig. 1. Case 1. A A double-contrast esophagram with patient's index finger pointing to the area of referred pain (arrow) during swallowing of barium sulfate mixture. B Doublecontrast esophagram shows several small linear ulcers in the aortic segment of the esophagus (arrows). C Endoscopic photograph of the esophagus shows small linear ulcers located circumferentially in the proximal thoracic esophagus 

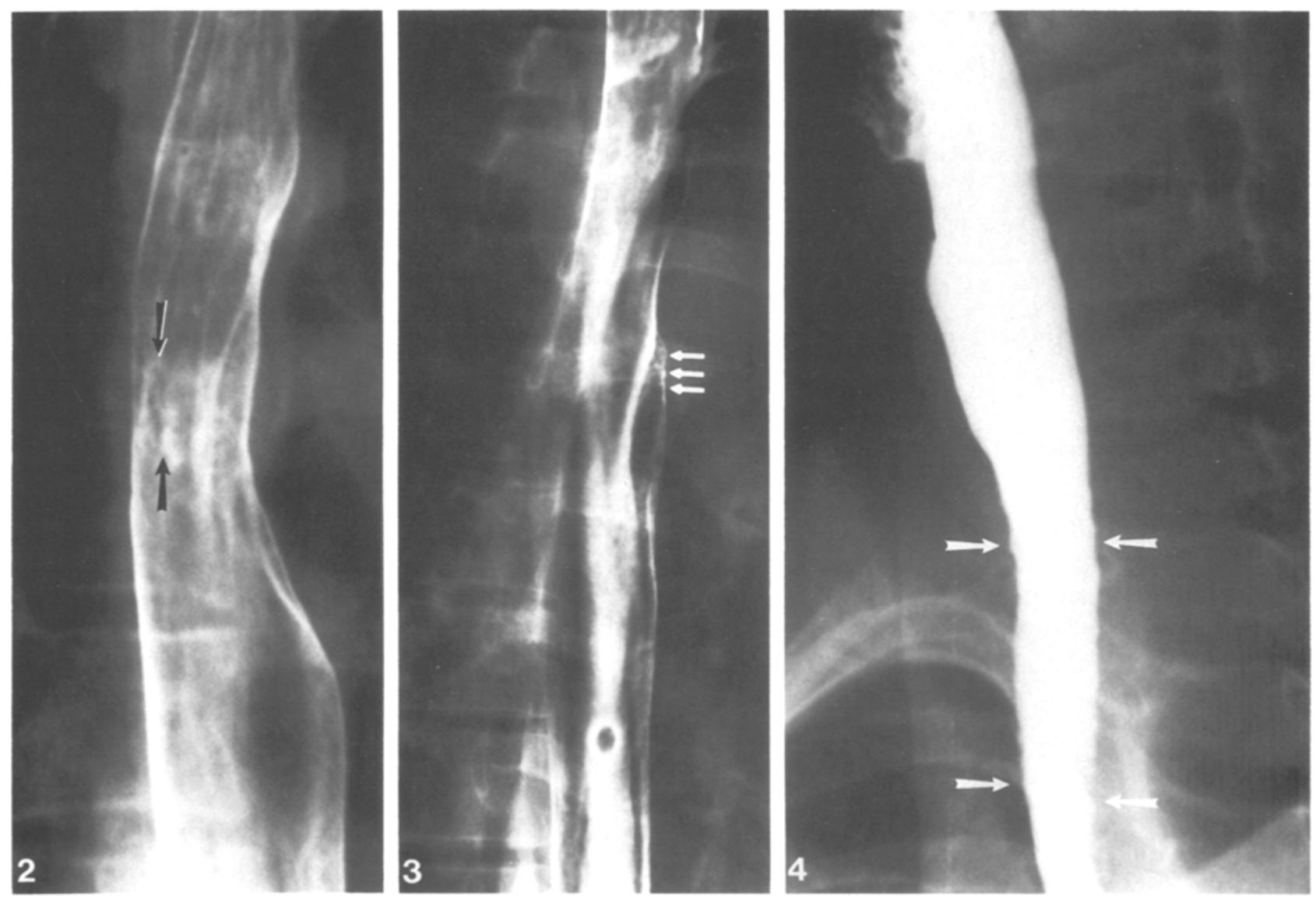

Fig. 2. Case 2. A double-contrast esophagram shows an oblong $1.5 \mathrm{~cm}$ ulcer in the aortic segment of the esophagus (arrows). The punctate barium collections above the ulcer probably represent small erosions

Fig. 3. Case 3. A double-contrast esophagram shows a cluster of shallow ulcers on the left wall of the aortic segment of the esophagus (arrows)

Fig. 4. Case 4. A single-contrast esophagram showing several mucosal irregularities in the proximal esophagus (arrows). Endoscopy confirmed the presence of several tiny ulcers and erosions

Esophageal brushing and a biopsy specimen from the area of ulceration revealed a fibrinopurulent exudate consistent with a benign ulcer. The patient was treated with antacids with good response and complete relief of symptoms in 5 days.

\section{Case 2}

A 25-year-old white woman complained of severe substernal pain and food sticking in the upper esophagus for 5 days. These symptoms were progressive and she was unable to eat solid or liquid food and lost about $4.5 \mathrm{~kg}$. Four days prior to onset of her symptoms she started taking tetracycline $250 \mathrm{mg}$ four times a day as a prophylaxis for removal of an intrauterine contraceptive device. On the 5th day she awoke with more severe substernal chest pain. The pain was relieved with antacids and recurred with the ingestion of solids or liquids. A double-contrast esophagram revealed a shallow ulcer in the aortic segment of the esophagus (Fig. 2). Endoscopic examination confirmed a discrete shallow ulcer approximately $23 \mathrm{~cm}$ from the incisors extending $1.5 \mathrm{~cm}$ distally. Pathologic examination of the biopsy specimen from the ulcer revealed fibrinopurulent exudate consistent with benign ulcer. The patient was advised to discontinue use of tetracycline and was treated with cimetidine liquid and antacids with excellent response and complete resolution of symptoms in 3 days. A repeat endoscopic examination 6 weeks later showed a completely healed esophageal ulcer.

\section{Case 3}

A 34-year-old white woman was in good health until 3 days before presenting, when she experienced substernal burning and food sticking in her upper esophagus. These symptoms had persisted despite administration of antacids. She had been taking doxycycline hyclate (Vibramycin ${ }^{\circledR}$ ) $250 \mathrm{mg}$ four times a day, as treatment for a "common cold" for 4 days prior to onset of present symptoms. A double-contrast esophagram (Fig. 3) revealed erosions and shallow discrete ulcerations in the aortic segment of the esophagus. No other abnormalities were seen. Endoscopic examination confirmed the presence of erosions and shallow ulcerations in the proximal esophagus about $24 \mathrm{~cm}$ from the incisors. The patient was advised to discontinue doxycycline and treated with antacids and cimetidine with complete resolution of symptoms within 3 days. 


\section{Case 4}

A 24-year-old white man complained of acute dysphagia and substernal pain following ingestion of ibuprofen (Motrin $\left.{ }^{(}\right) 4$ hours earlier. The patient also gave a history of several episodes of food or pills getting stuck in his esophagus in the past. He had been taking ibuprofen recently as treatment for neck/back injury. Endoscopic examination revealed discrete shallow ulcers $30 \mathrm{~cm}$ from the incisors and residual food particles (carrot pieces). An esophagram revealed shallow ulcers in the proximal esophagus and some dysmotility (Fig. 4). The patient was advised to discontinue Motrin ${ }^{(1)}$ and was treated with antacids and cimetidine liquid with good response and resolution of symptoms within 5 days.

\section{Discussion}

A wide variety of medications have been implicated in iatrogenic esophagitis. To date 85 cases have been published including the 4 cases in this report $[1-30]$. The most common drug reported to induce esophagitis has been emepronium (22 cases) $[14,23-25]$, followed by tetracycline (18 cases) $[7,9,12,15]$ and slow-release potassium chloride (14 cases). The other medications implicated have been Clinitest ${ }^{\circledR}$ tablets [13], quinidine $[12,22]$, fluorocil [27], pentaerythritol tetranitrate [4], doxycycline hyclate $[3,12,16]$, clindamycin $[28,29]$, ascorbic acid [8], cromolyn sodium [30], and ferrous sulfate [6]. Direct irritant effect of medication due to prolonged contact with esophageal mucosa appears to be the most likely factor. However, the acidic nature of some medications such as tetracycline hydrochloride and its derivatives [3, 7, 15-18], ascorbic acid [8], and ferrous sulfate [6] may also play a role. Slow clearance of the medication due to the large size of the tablet or abnormal esophageal motility may contribute to prolonged contact between the ingested medication and the esophageal mucosa. Delayed clearance of medications in a number of patients has been promoted by ingestion of medication, particularly with little or no water, immediately before going to bed. The predilection for involvement of the aortic segment of the esophagus by MIE may be due to the location of this transition zone between skeletal and smooth muscle. This segment may be subject to discoordinate peristaltic activity, therefore prolonging mucosal contact with ingested medication [8]. Underlying motility abnormalities may hinder effective passage of medication through the esophagus. This is suggested in our case 4 who presented with intermittent esophageal obstruction by medication and food. The esophageal ulcers presumably developed because of prolonged contact of the medication with the esophageal mucosa. Most pa- tients with MIE have no intrinsic esophageal disease. However, the patients with dysmotility or those with extrinsic compression on the esophagus causing luminal narrowing and functional stenosis are more prone to MIE $[10,11,22]$.

The clinical presentation is similar in all patients with MIE. There is usually a sudden onset of acute dysphagia accompanied by substernal chest pain or odynophagia within 4-12 hours after ingestion of the medication. In cases with quinidine-induced ulceration in the esophagus, symptoms may be delayed for several weeks $[12,22]$.

Endoscopically, MIE is usually seen in the proximal esophagus. These ulcers may be solitary or a cluster of tiny ulcers usually distributed circumferentially on a background of normal-appearing mucosa $[8,21]$. Endoscopic brush cytologic study may be helpful in differentiating these ulcers from virus-associated ulcers (herpes and cytomegalovirus).

Radiologically, conventional single-contrast esophagrams have shown deep ulcers or stricture in severe cases only. The early mucosal changes of superficial erosions and subtle shallow ulcers can be best demonstrated with a double-contrast esophagram [12]. The usual site of the localized esophagitis is the aortic segment of the esophagus, in contrast with reflux esophagitis which occurs in the distal esophagus. The ulcers of MIE appear as solitary or multiple shallow ulcers on one wall or may be distributed circumferentially in the proximal esophagus (case 1). Most ulcers are a few millimeters in size; however, occasionally a larger ulcer may be seen. In one of our patients (case 2) a $1.5 \mathrm{~cm}$ discrete ulcer was seen. This was probably due to contact of a broad area of mucosa with the medication. In some cases stricture formation due to quinidine has been reported $[12,22]$. This presumably occurs due to subacute or recurrent esophagitis induced by the medication.

\section{References}

1. Pemberton J: Oesophageal obstruction and ulceration caused by oral potassium therapy. Br Heart $J$ 32:267-268, 1970

2. Rosenthal T, Adar R, Militianu MD, Deutsch V: Esophageal ulceration and oral potassium chloride ingestion. Chest $65: 463-465,1974$

3. Bokey L, Hugh TB: Oesophageal ulceration associated with doxycycline therapy. Med $J$ Aust 1:236-237, 1975

4. Cummins EJ: Oesophageal obstruction by water insoluble medication. JAMA 196:917, 1966

5. McCall AJ: Slow-K ulceration of esophagus with aneurysmal left atrium. Br Med $J 3: 230-231,1975$

6. Abbarah TR, Fredell JE, Ellenz GB: Uiceration by oral ferrous sulphate. JAMA $236: 2320,1976$ 
7. Crowson TD, Head LH, Ferrante WA: Esophageal ulcers associated with tetracycline. JAMA 235:2747-2748, 1976

8. Walta DC, Giddens JD, Johnson LP, Kelley JL, Waugh DF: Localized proximal esophagitis secondary to ascorbic acid ingestion and esophageal motor disorder. Gastroentero$\log y 70: 766-769,1976$

9. Teplick JG, Teplick SK, Ominsky SH, Haskin ME: Esophagitis caused by oral medication. Radiology 134:23-25, 1980

10. Chesshyre MH, Braimbridge MV: Dysphagia due to left atrial enlargement after mitral Starr valve replacement. $\mathrm{Br}$ Heart $J$ 33:799-802, 1971

11. Whitney B, Croxon R: Dysphagia caused by cardiac enlargement. Clin Radiol 23:147-152, 1972

12. Creteur V, Laufer I, Kressel HY : Drug induced esophagitis detected by double contrast radiography. Radiology 147:365-368, 1983

13. Danzig LS, Loebel AS: Clinitest-tablet ingestion and stricture of the esophagus. JAMA 192:1092, 1965

14. Kavin H: Oesophageal ulceration due to emepronium bromide. Lancet 1:424 425, 1977

15. Channers KS, Hollanders D: Tetracycline induced esophageal ulceration. $\mathrm{Br} \mathrm{Med} J$ (Clin Res) 282:1359-1360, 1981

16. Schneider R: Doxycycline esophageal ulceration. Am J Dig Dis 22:805-807, 1977

17. Giger $M$, Sonnenberg A, Brandhi $H$, Singeisen $M$, Guller R, Blum AL: Das Tetracyclin Ulkus der Speiseröhre. Dtsch Med Wochenschr 103:1038-1040, 1978

18. Kobler E, Buhler H, Nuesch HJ, Dehyle P: Medikamentos induzierte osophagusulzera. Dtsch Med Woschenschr 103:1035-1037, 1978
19. Howie AD, Strachan RW: Slow release potassium chloride treatment. $\mathrm{Br}$ Med J 1:176, 1976

20. Kenwright $S$, Norris ADC: Oesophageal ulceration occurring secondary to slow release potassium tablets. Ir $J \mathrm{Med}$ Sci 144:366, 1975

21. Mason SJ, O'Meara TF: Drug induced esophagitis. $J$ Clin Gastroenterol 3:115-120, 1981

22. Bohane TD, Perrault J, Fowler RS: Oesophagitis and esophageal obstruction from quinidine tablets in association with left atrial enlargement: a case report. Aust Paediatr J 14:191-192, 1978

23. McCloy RF: Oesophageal ulceration due to emepronium bromide. Lancet 1:548, 1978

24. Bennett JR: Oesophageal ulcerations due to emepronium bromide. Lancet 1:810, 1977

25. Higson RH: Oesophagitis as a side effect of emepronium. Br Med J 1:201, 1978

26. Puhakka JH: Drug-induced corrosive injury of the esophagus. J Laryngol Otol 92:927-931, 1978

27. Collins FJ, Mathews HR, Baker SE, Strakova JM: Drug induced esophageal injury. $\mathrm{Br} \mathrm{Med} J \mathrm{~J}$ 1:1673-1676, 1979

28. Sutton DR, Gosnold JK: Oesophageal ulceration due to clindamycin. Br Med J 1:1598, 1977

29. Froese EH: Oesophagitis with clindamycin. $S$ Afr Med $J$ $56: 826,1979$

30. Israel RH, Wood J: Esophagitis related to cromolyn. JAMA 242:2758-2759, 1979

Received: September 25, 1984; accepted: December 6, 1984 